\title{
Toxicity assessment of water at different stages of treatment using Microtox assay
}

\author{
Marta Pogorzelec ${ }^{1, *}$, and Katarzyna Piekarska ${ }^{1}$ \\ ${ }^{1}$ Wroclaw University of Science and Technology, Faculty of Environmental Engineering, Wybrzeże \\ Wyspiańskiego 27, 50-370 Wrocław, Poland
}

\begin{abstract}
Number of potentially toxic hydrophobic organic contaminants e.g. polycyclic aromatic hydrocarbons, pesticides, polychlorinated biphenyls and dioxins having entered aquatic environment, including potential sources of drinking water. Unfortunately, not all micropollutants can be removed during water treatment processes. What is more, disinfectants can react with some organic compounds already present in the water, and form disinfection by-products which also can be toxic. The aim of this study was to assess toxicity of water at different stages of water treatment and to verify usefulness semipermeable membrane devices in monitoring of drinking water. For this purpose, semipermeable membrane devices (SPMDs) were deployed in a surface water treatment plant. To determine the effect of water treatment on the presence of toxic micropollutants, study was conducted for a period of 5 months. Three sampling places were chosen: raw water input, stream of water just before disinfection and treated water output. After sampling dialysis in organic solvent was carried out and extracts were then analyzed with the Microtox acute toxicity test. The study has indicated the utility as well as some limitations of combining SPMDs with bioluminescence assay in the monitoring of biological effects of bioavailable hydrophobic pollutants in drinking water.
\end{abstract}

\section{Introduction}

Surface water, in comparison with the groundwater, contains an increased number of microbiological and chemical contaminants [1, 2]. Many of organic micropollutants, including polycyclic aromatic hydrocarbons (PAHs), pesticides, dioxins and polichlorinated biphenyles, could be a hazard to the living organisms, because of their toxic potential $[3,4]$. Therefore, it is necessary to carry out water treatment processes in order to enable it to human consumption. One of the main stages of water tratment is disinfection, which allows to eliminate or minimize the bacteriological risk. The purpose of disinfection is to destroy the living and spore forms of pathogenic organisms and preventing their redevelopment in the water distribution system. Insufficiently effective disinfection or lack thereof are the cause of waterborne diseases. Disinfection of water by chemical methods is the addition of strong oxidants. However, disinfectants (most frequently chlorine,

* Corresponding author: marta.pogorzelec@pwr.edu.pl 
chlorine dioxide and ozone) can react with chemicals already present in water, that can lead to a number of other hazardous substances, referred as disinfection by-products (DBPs), which also may be toxic, genotoxic and carcinogenic [1-5].

Detection of micropollutants at low concentrations is extremely difficult. Accordingly, the water sample containing contaminants should be concentrated prior to analysis. Classical methods require the transport of large quantities of water from sampling places to laboratory, which creates logistical problems. To avoid this, in recent years popularity of passive samplers, including semipermeable membrane devices (SPMDs) has increased [6-10]. Semipermeable membrane devices are designed for concentration of the hydrophobic organic compounds present in water and air environments. SPMD is consisting of a neutral lipid with high molecular weight $(>600 \mathrm{Da})$, the most often triolein, sealed within a thin wall of low density polyethylene (LDPE) tube. The polyethylene membrane is considered to be non-porous, but the random thermal motions of the polymer chain leads to the formation of instantaneous cavities with maximum diameter of $10 \AA$. These membrane mimicking the biological membranes, thus allow selective diffusion of dissolved low molecular weight organic compounds, and their condensation in triolein $[11,12]$.

The combination of semipermeable membrane devices with bioassays allows the assessment of toxic or genotoxic potential of environmental samples. The effectiveness of the method has been demonstrated for short-term bioassays, including Microtox ${ }^{\mathrm{TM}}$ and Daphnia pulex toxicity analysis [7, 8,13-15].

\section{Materials and methods}

\subsection{SPMDs deployment}

Semipermeable membrane devices of the standard configuration $(91.4 \mathrm{~cm}$ long, $2.5 \mathrm{~cm}$ wide, membrane thickness $70-95 \mu \mathrm{m}$, containing $1 \mathrm{ml}$ of $99 \%$ purity triolein) from ExposMeter AB (Tavelsjö, Sweden) were deployed in in a surface water treatment plant called "Mokry Dwór" located in Lower Silesia, nearby Wrocław (Poland). Three places were chosen for sampling: A- pumping station "Czechnica" as a raw water input, $\mathrm{B}$ - pipeline with a stream of water just before ozone disinfection and C-clean water tank as a treated water output. Characteristics of the sampling points is described below.

In the study, samples were taken monthly over a period of about five months (II-VI : February 2016-July 2016), which means that after every month membranes were exchanged. Exceptions were membrane labeled "III-IV" (March 2016- April 2016), which, due to technological problems at the water treatment plant, remained in water for about eight weeks. Each membrane represents the state of water in a given month.

\subsection{Characteristics of sampling places}

\subsubsection{A- Pumping station "Czechnica"- raw water input}

The water that flows into the pumping station "Czechnica" is surface water without any treatment from the Oława River. The river has a length of $91.7 \mathrm{~km}$ and a catchment area of 1167.4 square kilometers. The source of Oława is in the Sudeten Foreland at an altitude of about 315 meters above sea level. Its composition is heavily dependent on the seasons. This water is characterized by high content of suspensions, colloids and dissolved organic compounds. In comparison with infiltrated or groundwater is characterized by a low content of minerals such as manganese and iron. 


\subsubsection{B-Pipeline- stream of water just before ozonation}

The water stream leaving the sand filter is free of suspensions, both those present in the raw water input, as well as those formed during the coagulation process. Organic compounds affecting the taste and odor are still present. To remove them effectively on a carbon filters, ozone is used to breaking them into smaller molecules, which increases the biodegradability of organic compounds. Generated during ozonation disinfection byproducts are adsorbed on a bed of coal or decomposed by a biomass in the bed.

\subsubsection{C-Clean water tank- stream of water after disinfection}

In the clean water tank there is a water after complete treatment and disinfection with chlorine dioxide. The water from this tank is collected and pumped directly to the water supply network. This water meets the requirements of water intended for human consumption in accordance with the Regulation of the Minister of Health in Poland. The dose of disinfectant dispensed before the clean water tank must be large enough to prevent secondary bacterial contamination of the water supply system.

\subsection{Samples preparation}

After one month of sampling SPMDs were transported to the laboratory where mechanical and chemical cleaning was carried out according to good SPMDs practice [16]. Then membranes were dialyzed separately in $130 \mathrm{~cm}^{3}$ of n-hexane to release compounds bounded in membrane. After 18 hours of dialysis in $18^{\circ} \mathrm{C}$ the solvent was replaced with fresh one $\left(130 \mathrm{~cm}^{3}\right)$ and dialysis was continued for another 8 hours. Then n-hexane has been completely removed using the rotary evaporation. The extracts intended for the Microtox ${ }^{\mathrm{TM}}$ analysis were dissolved in $5 \mathrm{~cm}^{3}$ of dimethyl sulfoxide (DMSO).

\subsection{Microtox ${ }^{\mathrm{TM}}$ toxicity analysis}

The Microtox ${ }^{\mathrm{TM}}$ toxicity analysis is based on bioluminescence of the marine bacteria Vibrio fisheri. Luminescent bacteria emit light when they are in optimal environmental conditions. Presence of toxic substance causes change of cellular state, which is rapidly reflected in a decrease of light emission [17]. The analysis with the Microtox ${ }^{\mathrm{TM}}$ Basic Test ware carried out following the standard procedures of the manufacturer. Fourteen double dilutions of each sample (A, B, C), solvent (hexane) and diluent (DMSO) were prepared. The luminescence intensity was measured with the Microtox ${ }^{\mathrm{TM}}$ Model 500 Analyzer at 0-, 5- and 15-min exposure time. For the calculations of percent inhibition of light emission, the following equations were used:

$$
\begin{gathered}
R_{t}=\frac{I_{c t}}{I_{c 0}} \\
G_{t}=\frac{R_{t} \times I_{s 0}}{I_{s t}}-1 \\
\% \text { inhibition }=\frac{G_{t}}{1+G_{t}} \cdot 100
\end{gathered}
$$


where $R_{t}$ is a correct for any inhibition induced by a negative control sample (blank cuvette) and $I_{c 0}$ and $I_{c t}$ are the absolute light intensities produced by the negative control at time $t$ and at initial time 0 , respectively. $I_{s 0}$ and $I_{s t}$ are the light intensities produced by water sample at time $t$ and at initial time 0 , respectively. $G_{t}$ is the ratio of the light lost at time $t$ to the light remaining at time $\mathrm{t}$, which can be convert to $\%$ inhibition. The final expression of the samples toxic response is presented as $\mathrm{EC}_{50}$ which is the Effective Concentration of the samples which reduces the light emission by $50 \%$, and was estimated from the linear regression of the log of each concentration level of the contaminant versus the percent inhibition. It was expressed as the amount of SPMD triolein [mg] per $1 \mathrm{~cm}^{3}$ of sample [18-19]. The toxicity equivalents, calculated as $1 / \mathrm{EC}_{50}$, ware used for graphical representation of the data.

\section{Results and discussion}

The analysis results of acute toxicity test Microtox TM are shown in Table 1 and in Figures 1-6, as $\mathrm{EC}_{50}$ values and $1 / \mathrm{EC}_{50}$ values after an exposure time of 5 and $15 \mathrm{~min}$.

Table 1. $\mathrm{EC}_{50}$ and $1 / \mathrm{EC}_{50}$ parameter values after 5 and 15 min exposition for water samples from different stages of treatment (A: pumping station- raw water input; B: pipeline- stream of water just before ozonation; C: clean water tank), in particular months (II-VI).

\begin{tabular}{|c|c|c|c|c|}
\hline \multirow{2}{*}{ Sample } & \multicolumn{2}{|c|}{ EC50 } & \multicolumn{2}{c|}{$\mathbf{1 / E C 5 0}$} \\
\cline { 2 - 5 } & $\mathbf{t = 5}$ & $\mathbf{t = 1 5}$ & $\mathbf{t}=\mathbf{5}$ & $\mathbf{t}=\mathbf{1 5}$ \\
\hline diluent & 3.583 & 2.659 & 0.279 & 0.376 \\
\hline hex & 1.382 & 3.065 & 0.724 & 0.326 \\
\hline II A & 0.668 & 0.467 & 1.496 & 2.143 \\
\hline II B & 1.049 & 0.702 & 0.953 & 1.424 \\
\hline II C & 0.808 & 0.509 & 1.238 & 1.963 \\
\hline III-IV A & 0.334 & 0.199 & 2.994 & 5.015 \\
\hline III-IV B & 0.422 & 0.300 & 2.372 & 3.338 \\
\hline III-IV C & 0.355 & 0.190 & 2.816 & 5.252 \\
\hline V A & 0.366 & 0.240 & 2.730 & 4.163 \\
\hline V B & 0.422 & 0.264 & 2.371 & 3.791 \\
\hline V C & 0.474 & 0.272 & 2.109 & 3.681 \\
\hline VI A & 0.367 & 0.247 & 2.721 & 4.055 \\
\hline VI B & 0.466 & 0.362 & 2.144 & 2.765 \\
\hline VI C & 0.568 & 0.403 & 1.760 & 2.483 \\
\hline
\end{tabular}

In the analysis of the toxicity test Microtox ${ }^{\mathrm{TM}}$ a positive effect of treatment processes at the level of toxicity of water has been observed. In some cases, after disinfection toxicity has grown, but still it was lower value than value for the raw water. Toxicity was changing with each month, however, to be able to draw accurate conclusions related to the impact of weather conditions on the level of toxicity of water, observation should be conducted for a longer time, at least for one year.

The results obtained for the solvents (n-hexan, DMSO) used to prepare samples for analysis (cleaning, dialysis, dissolving material) indicates that these did not have any additional contaminants and their impact on the results was negligible. 


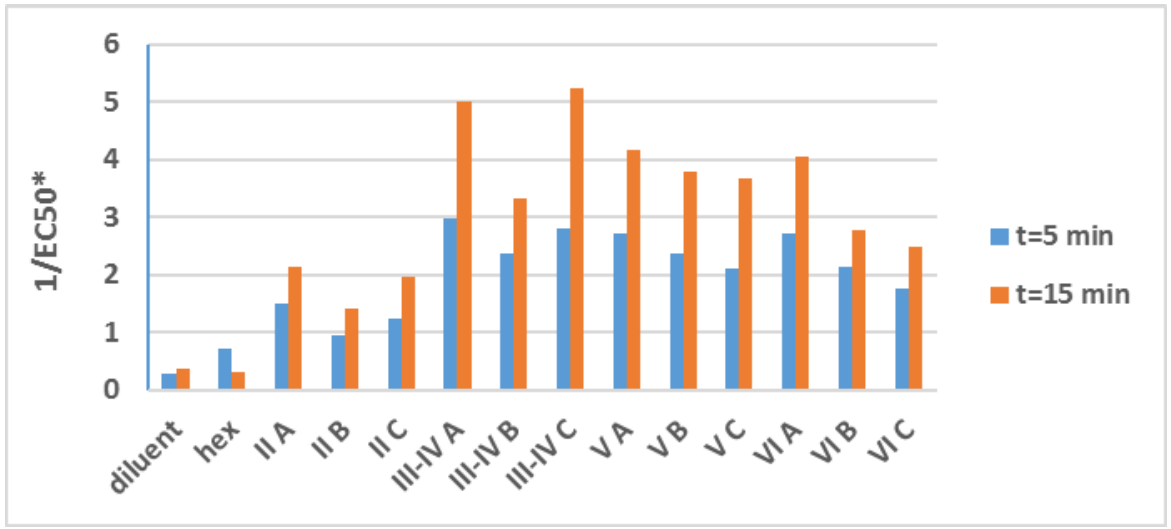

Fig. 1. 1/EC $\mathrm{E}_{50}$ parameter values after 5 and $15 \mathrm{~min}$ exposition for water samples from different stages of treatment (A: pumping station- raw water input; B: pipeline- stream of water just before ozonation; C: clean water tank), in particular months (II-VI).

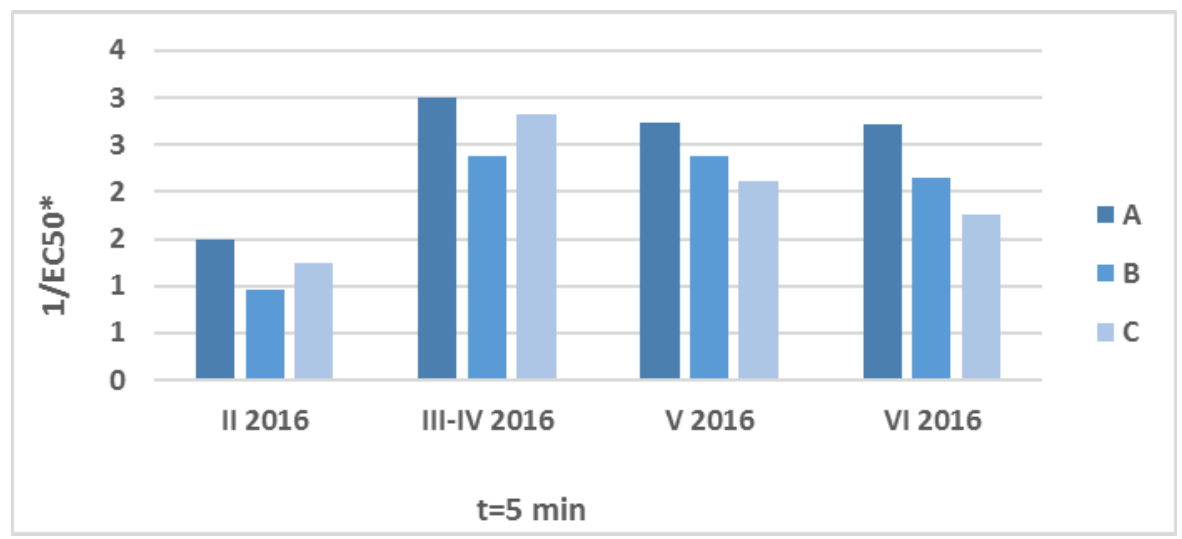

Fig. 2. 1/EC $\mathrm{E}_{50}$ parameter values after $5 \mathrm{~min}$ exposition for water samples from different stages of treatment (A: pumping station- raw water input; B: pipeline- stream of water just before ozonation; $\mathrm{C}$ : clean water tank), in particular months (II-VI).

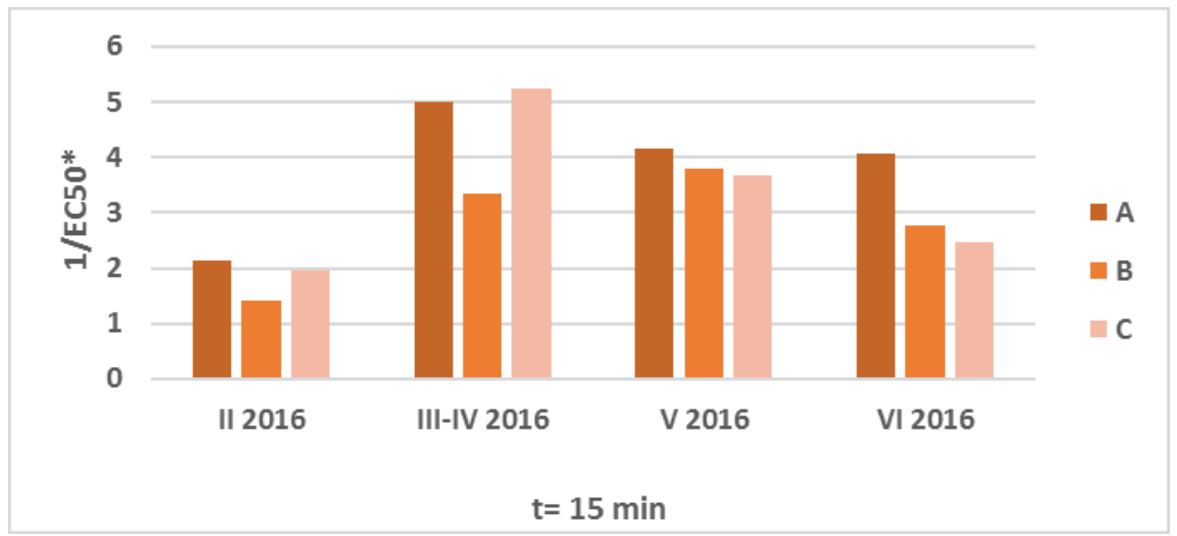

Fig. 3. $1 / \mathrm{EC}_{50}$ parameter values after $15 \mathrm{~min}$ exposition for water samples from different stages of treatment (A: pumping station- raw water input; B: pipeline- stream of water just before ozonation; C: clean water tank), in particular months (II-VI). 


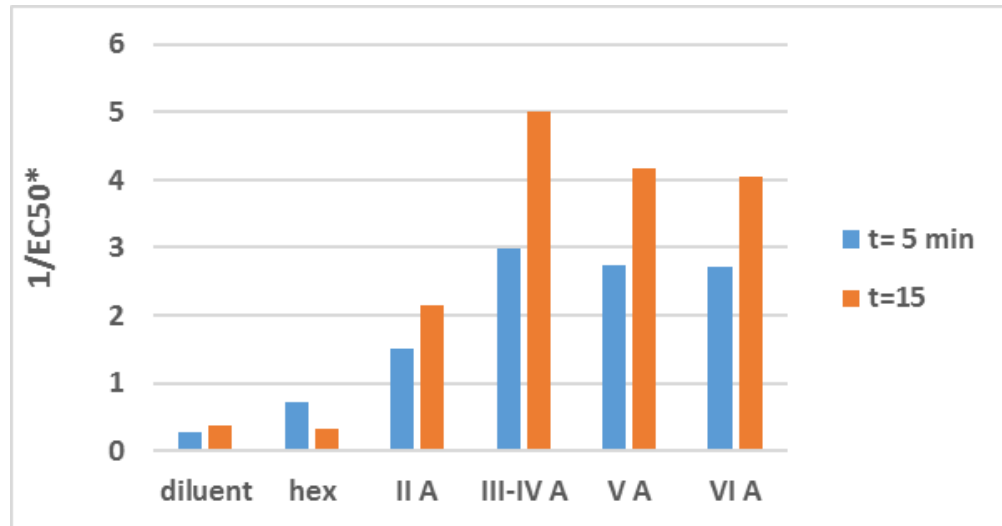

Fig. 4. 1/EC 50 parameter values after 5 and 15 min exposition for water samples from sampling place A (pumping station- raw water input), in particular months (II-IV).

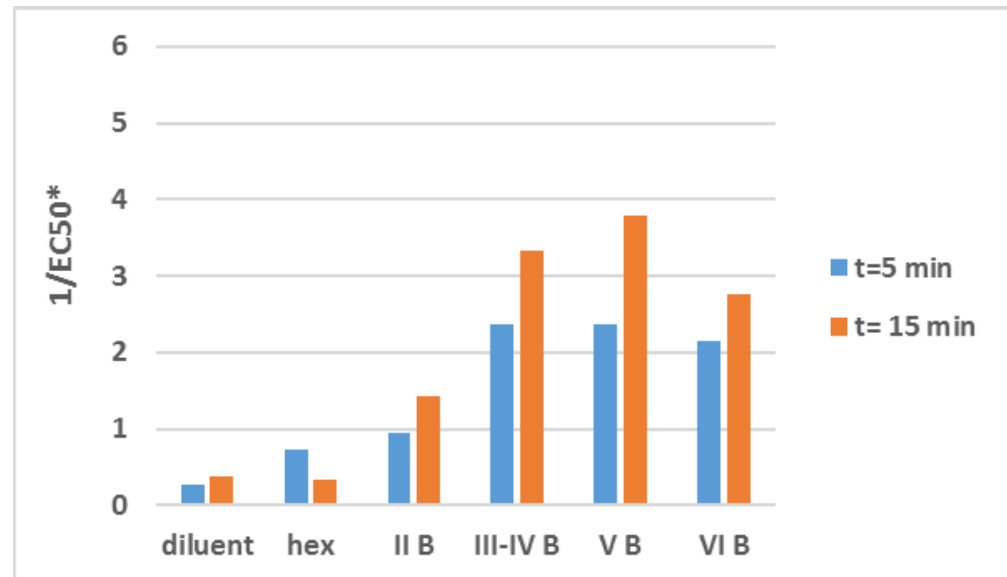

Fig. 5. $1 / \mathrm{EC}_{50}$ parameter values after 5 and $15 \mathrm{~min}$ exposition for water samples from sampling place B (pipeline- stream of water just before ozonation), in particular months (II-IV).

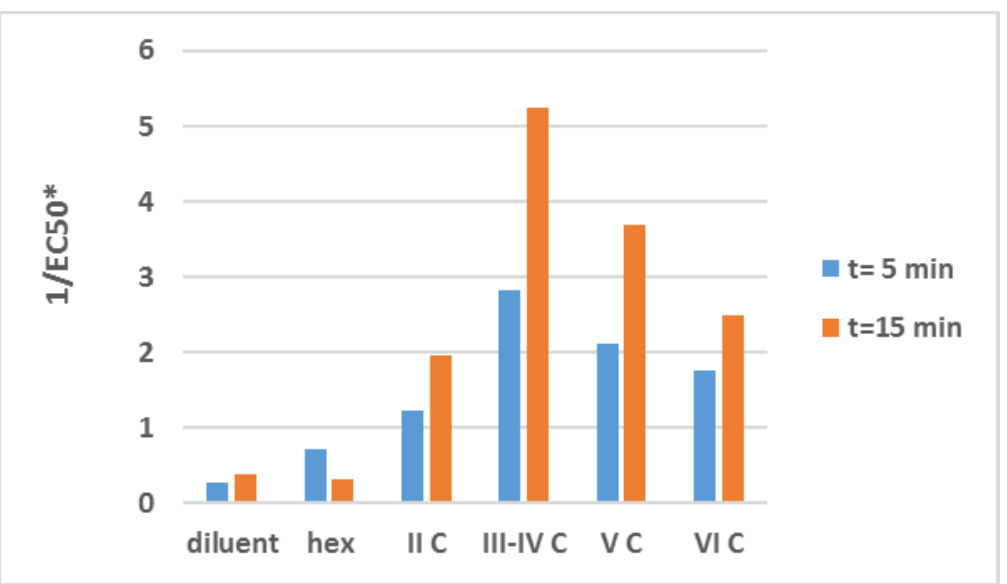

Fig. 6. $1 / \mathrm{EC}_{50}$ parameter values after 5 and $15 \mathrm{~min}$ exposition for water samples from sampling place $\mathrm{C}$ (clean water tank), in particular months (II-IV). 


\section{Conclusions}

The current "bottleneck" of biological assays is problem with concentration of investigated compounds. Due to low concentration of micropollutants in water, it is necessary to fit appropriate technique for concentration of them in order to be detectable during the chemical and biological analysis. The proposed method uses passive samplers with semipermeable membrane, which are placed directly at the place of sampling, what eliminates logistical problems.

The study indicates that the use of semipermeable membrane devices can be an effective tool for the analysis of the aquatic environment, in which organic micropollutants are present at very low concentrations. Nevertheless, analysis of the toxicity of water at different stages of treatment should be conducted for a longer term, to take into account the impact of changing weather conditions on obtained results. Moreover, this analysis should also be supplemented by chemical analyzes and genotoxicity assays, to determine the health quality of water and its impact on living organisms.

The research financed by the funds of the Ministry of Science and Higher Education for young scientist and doctoral students order number: B50557.

\section{References}

1. J. Fawell, M. J. Nieuwenhuijsen, Brit. Med. Bull. 68, 199-208 (2003)

2. M. Świderska-Bróż, Mikrozanieczyszczenia w środowisku wodnym, (Wydawnictwo Politechniki Wrocławskiej, Wrocław, 1993)

3. L. Kowal, M. Świderska-Bróż, Oczyszczanie wody (PWN, Warszawa, 2007)

4. C. Zani, D. Feretti, A. Buschini, P. Poli, C. Rossi, L. Guzella, F. Di Caterino, S. Monarca, Res. 587, 26-37 (2005)

5. S. D. Richardoson, Trend. Anal. Chem. 22, 666-684 (2003)

6. W.L. Cranor, D.A. Alvarez, S.D. Perkins, G.A. Tegerdine, R.C. Clark, J. N. Huckins, Use of semipermeable membrane device (SPMD)technology for a probabilistic assessment of hydrophobic organic contaminants in selected reaches of Virginia rivers (U. S. Geological Survey, 2005)

7. G. Gilli, T. Schiliro, Pignata, D. Traversi, E. Carraro, C. Baiocchi, R. Aigotti, D. Giacosa, E. Fea, Chemosphere 61, 1691-1699 (2005)

8. Y. Lu, Z. Wang, J. Huckins, Aquat. Toxicol. 60, 139-153 (2002)

9. A. Marrucci, B. Marras, S.S. Campisi, M. Schintu, Mar. Pollut. Bull. 75, 69-75 (2013)

10. J.F. Mueller, M.R. Mortimer, J. O’Brein, T. Komarova, S. Carter, Mar. Pollut. Bull. 63, 73-76 (2011)

11. J.N. Huckins, J.A. Lebo, M.W. Tubergen, G.K. Manuweera, V.L. Gibson, J.D. Perry, United States Patent, Patent Number 5,098,573 (1992)

12. J.N. Huckins, Fundamentals of SMPDs. Monitors of organic chemicals in the environment (Springer, 2006)

13. J.D. Petty, J.N. Huckins, S.B. Jones, T.P. Boyle, Chemosphere 41, 311-321 (2000)

14. D. Sabaliūnas, J.R. Lazutka, I. Sabaliuniene, Environ. Pollut. 109, 251-265 (2000)

15. D. Sabaliūnas, A. Södergren, Environ. Pollut. 96, 195-205 (1997) 
16. D. Alvarez, Guidelines for the use of the semipermeable membrane device (SPMD) and the polar organic chemical integrative sampler (POCIS) in environmental monitoring studies, (U.S. Geological Survey, Techniques and Methods 1-D4 2010)

17. G. Węgrzyn G., A. Czyż, Oceanologia 44, 291-305 (2002)

18. I.D. Gaudet, Standard Procedure for MICROTOX Analysis. WCMUC (1994)

19. R. James, Strategic Diagnostics Inc. Microtox ${ }^{\circledR}$ Rapid Toxicity Testing System. Environmental Technology Verification Report (U.S. EPA, 16-17, 2003) 